\title{
Schizophrenic behavior of 2,3-oxidosqualene sterol cyclase from pig liver towards 2,3-oxidosqualene analogs
}

\author{
Alain Krief ${ }^{1,{ }^{*}}$, Romuald Sable ${ }^{1}$, Alain Ronvaux ${ }^{1}$, Willy Dumont ${ }^{1}$, Pat Sandra ${ }^{2}$, Frank David ${ }^{2}$ \\ ${ }^{1}$ Chemistry department, University of Namur, Namur B-5000, Belgium. \\ ${ }^{2}$ Research Institute for Chromatography, Kortrijk B-8500, Belgium. \\ ${ }^{\star}$ Correspondence to: Prof. Alain Krief, Chemistry Department, University of Namur, 61 Rue de Bruxelles, Namur B-5000, Belgium. \\ E-mail: alain.krief@unamur.be

\begin{abstract}
How to cite this article: Krief A, Sable R, Ronvaux A, Dumont W, Sandra P, David F. Schizophrenic behavior of 2,3-oxidosqualene
\end{abstract} \\ sterol cyclase from pig liver towards 2,3-oxidosqualene analogs. Chem Synth 2021;1:6. https://dx.doi.org/10.20517/cs.2021.03
}

Received: 3 Jun 2021 First Decision: 19 Jul 2021 Revised: 21 Jul 2021 Accepted: 3 Aug 2021 First online: 3 Aug 2021

Academic Editor: Bao-Lian Su Copy Editor: Yue-Yue Zhang Production Editor: Yue-Yue Zhang

\begin{abstract}
We report the unusual behavior of oxidosqualene sterol cyclase from pig liver towards 2,3-oxidosqualene analogs bearing two alkyl groups different from a methyl, at their $\Delta^{18-19}$ double bond: unambiguous structure determinations of the products and tentative rational for their formation are described.
\end{abstract}

Keywords: Biosynthesis, multistep hemi-synthesis of natural product analogs, performance liquid chromatography, structure determination

\section{INTRODUCTION}

The transformation of linear squalene to $(20 R)$-lanosterol $(R)$-3a possessing four cycles and seven chiral centers, by membrane-bound oxidosqualene sterol cyclase (OSC; lanosterol synthetase), has been the subject of constant interest for more than 70 years ${ }^{[1-5]}$. Woodward and $\mathrm{Bloch}^{[6]}$ first proposed that lanosterol is an intermediate in the transformation of squalene to cholesterol, and soon after Stork ${ }^{[7,8]}$ and the Zurich School ${ }^{[9,10]}$ independently proposed a detailed mechanism for the construction of the steroid scaffold [Scheme 1]. 


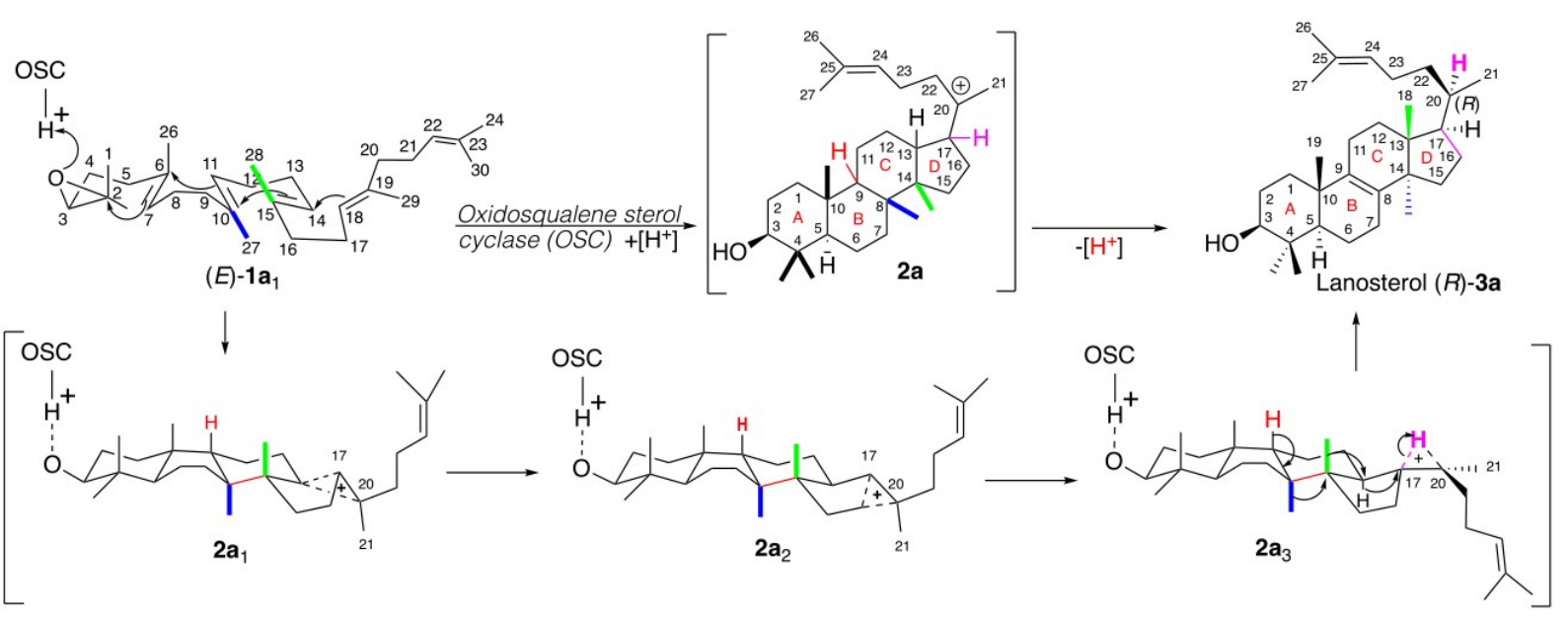

Scheme 1. Description of the Zurich School mechanism from all (E)2,3-oxidosqualenes to lanosterol.

The original description of this mechanism [Scheme 1], adapted to the discovery by Corey et al. ${ }^{[11]}$ and Van Tamelen et al ${ }^{[12]}$ that 2,3-oxidosqualene $(E)-1 \mathrm{a}$ is intermediate in this transformation, involves: (i) a polycyclization, implying its $\Delta^{6-7}, \Delta^{9-10}, \Delta^{13-14}$, and $\Delta^{18-19}$ double bonds, initiated by an acid catalyst part of the enzyme and prefolded by the enzyme in a chair-boat-chair-boat conformation; (ii) this leads to the formation of the elusive intermediate 2 a named "protosterol", possessing a 6,6,6,5-membered polycyclic scaffold $(\mathrm{A} / \mathrm{B} / \mathrm{C} / \mathrm{D})$ and bearing a tertiary carbocation at C-20 (steroid nomenclature) on the side chain lying in $\alpha$-position; and (iii) a series of 1,2 -shifts on the latter, ending by the loss of the $\left(\mathrm{H}_{9}\right)$ proton delivering lanosterol $(R)$-3a possessing a $\Delta^{8-9}$ double bond (steroid nomenclature, Scheme 1).

The proposed mechanism is based on two stereochemical assumptions supported by strong experimental evidence: (i) antiperiplanar addition across each $\mathrm{C}=\mathrm{C}$ double bond; and (ii) suprafacial 1,2-shifts driving each migration $\left(\mathrm{H}_{17}, \mathrm{H}_{13}, \mathrm{Me}_{14}\right.$, and $\left.\mathrm{Me}_{8}\right)$.

However, this proposal leads to a protosterol with an alpha-oriented side chain whose stereochemistry at C20 formerly requires a $120^{\circ}$ clockwise rotation around the $\mathrm{C}_{17}-\mathrm{C}_{20}$ bond to initiate the series of migrations leading to the lanosterol possessing the natural $(20 R)$-stereochemistry. This is sketched ${ }^{[9,10]}$ in the original proposal by a series of non-classical ion rearrangements $\left(2 \mathbf{a}_{1} \rightarrow 2 \mathbf{a}_{2} \rightarrow 2 \mathbf{a}_{3}\right.$, Scheme 1$)$.

It was then rationalized by Cornforth ${ }^{[13]}$, who hypothesized that the protosterol should resemble $\mathbf{2} \mathrm{a}_{4}$ bearing an exogeneous X group at C-20 on the side chain lying in $\alpha$-position. It results from: (i) the folding of the polyene originally in a chair-boat-chair-boat conformation $(E)-1 \mathbf{a}_{1}$ as previously reported by the Zurich School (Scheme 2, entry a); (ii) a series of concerted anti-addition of the different $[\mathrm{C}=\mathrm{C}]$ double bonds ending by the addition on the $\left[\mathrm{C}_{b}=\mathrm{C}_{c}\right]$ double bond of $\left[\mathrm{C}_{\mathrm{a}}\right]$ (from the re face) on $\left[\mathrm{C}_{b}\right]$ and an exogeneous $\mathrm{X}$ group at $\left[\mathrm{C}_{\mathrm{c}}\right]$ (from the re face) that produces concomitantly the $\mathrm{D}$ ring; and (iii) a $120^{\circ}$ clockwise rotation of the side chain, located in $\alpha$-position, around the $\left[\mathrm{C}_{\mathrm{b}}-\mathrm{C}_{\mathrm{c}}\right]$ single bond leading to $2 \mathrm{a}_{4}$, in which the $\mathrm{C}_{\mathrm{b}}-\mathrm{X}$ bond is aligned with the $\mathrm{C}_{\mathrm{b}}-\mathrm{H}$ bond in an antiperiplanar conformation that initiates the departure of the $\mathrm{X}$ group and the series of migrations leading to the (20R)-lanosterol (20R)-3a (Scheme 2, entry a).

The Corey proposal (Scheme 2, entry b) ${ }^{[14,15]}$ avoids the $120^{\circ}$ rotation implied in each of the previous mechanisms by involving the intermediate formation of a protosterol $2 \mathbf{a}_{5}$ resulting from a chair-boat-chairchair folding of the 2,3-oxidopolyene (E)-1 $\mathbf{a}_{2}$, different from the above, and bearing its side chain in $\beta$ - 


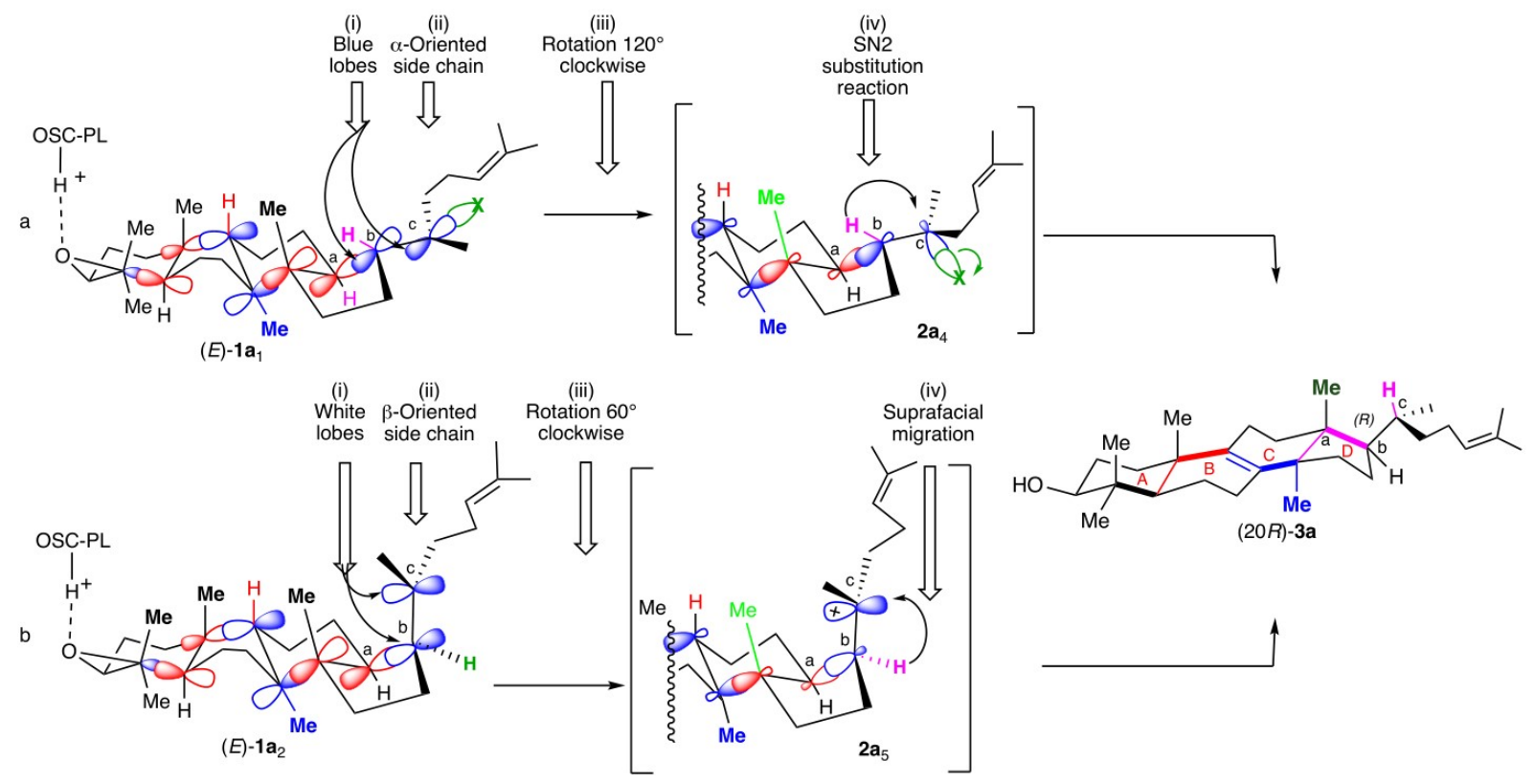

Scheme 2. Cornforth (entry a) and Corey (entry b) mechanisms accounting for the (R)-stereochemistry of lanosterol 3a at C-20.

position. It accordingly results from the attack of $\mathrm{C}_{\mathrm{a}}$ by the si face of $\mathrm{C}_{\mathrm{b}}$ (Scheme 2, entry $\mathbf{b}$ ). A rotation of the chain of only $60^{\circ}$ clockwise around the $\mathrm{C}_{b}-\mathrm{C}_{c}$ allows the alignment of the $\mathrm{C}_{b}-\mathrm{H}$ bond with the $\pi$-bond of the carbocation at $\mathrm{C}_{\mathrm{c}}$ and initiates the series of migrations leading to the (20R)-lanosterol $(20 R)-3 \mathrm{a}$ (Scheme 2, entry b $)^{[1-5,14,15]}$.

The latter mechanism, experimentally supported ${ }^{[14,15]}$ by isolation of a stable protosterol analog in which the carbocation at $\mathrm{C}-20$ is trapped by water from a suitable oxidosqualene analog, is now generally admitted ${ }^{[1-5]}$.

Since the polycyclization process ends and the series of migration starts at the C-20 carbon, we expected to obtain precious information on the whole process by looking at what happens there. We therefore initiated, a long ago, a research program ${ }^{[16-18]}$ aimed at gathering the behavior of oxidopolyenes analogs that differ from the original by the nature of the substituents at C-19 and the stereochemistry of their $\Delta^{18-19}$ double bond towards oxidosqualene sterol cyclases extracted from mammals (pig liver, OSC-PL) or yeast (Saccharomyces cerevisiae, OSC-SC).

\section{RESULTS AND DISCUSSION}

We report the first example of a transformation of an oxidosqualene analog by OSC-PL that leads to a mixture of lanosterol analog epimers at C-20 whose formation relates to carbocationic protosterols in which the side chain lies for the major one in the $\beta$-position, as disclosed in the Corey mechanism (Scheme 2, entry b), and for the minor one in the $\alpha$-position, as originally proposed in the Zurich-Stork mechanism (detailed in part in Scheme 2, entry a). These results contrast with previous results from our laboratory involving related oxidosqualene analogs that exhibit complete stereocontrol.

We previously reported that oxidosqualene analogs $(E)-\mathbf{1 b}$ and $(Z)-\mathbf{1 b}$ possessing a methyl and an ethyl group at C-19 with the natural $(E)$ - and the unnatural $(Z)$-stereochemistry at their $\Delta^{18-19}$ double bond are mainly cyclized by OSC-PL to lanosterol analogs $3 \mathbf{b}$ that only differ from their stereochemistry at C-20, along with a few percent of the tricyclic compounds $\mathbf{5 b}$ resulting from a partial polycyclization (Scheme 3 , 


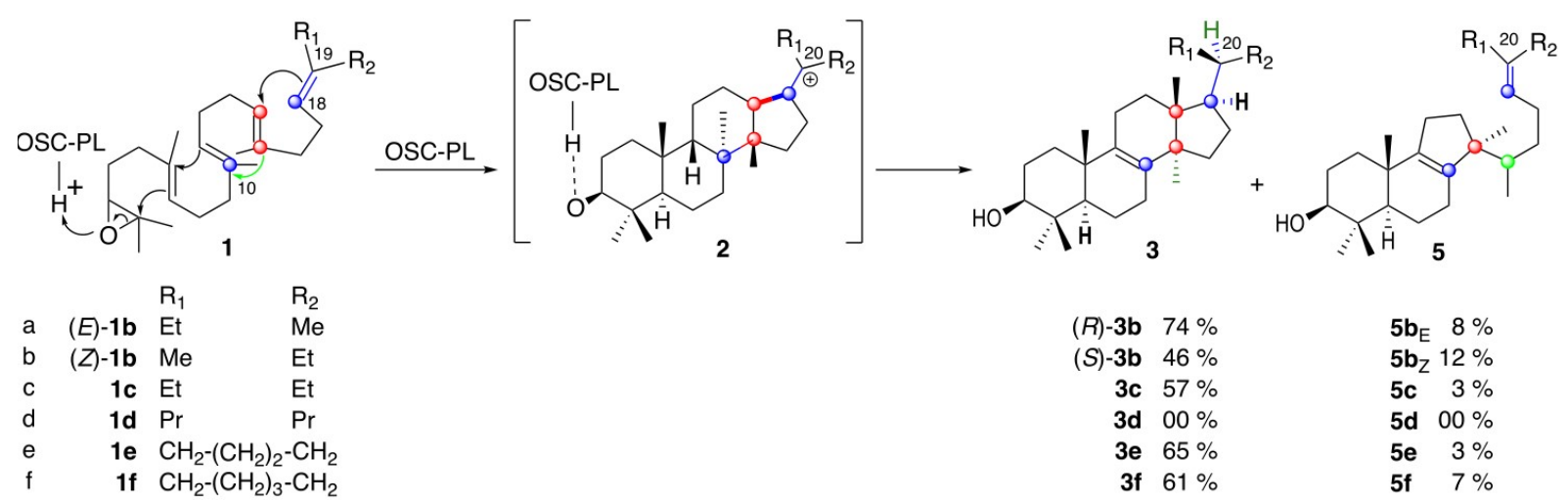

Scheme 3. Results concerning the transformation of truncated 2,3-oxidosqualene analogs by OSC-PL.

compare entries $\mathbf{a}$ and $\mathbf{b})^{[16,17]}$.

However, the reaction of OSC-PL ${ }^{[19]}$ with the 2,3-oxidosqualene analog $(Z)$-1a possessing the same hydrocarbon framework as the natural product $(E)-1$ a but inverted stereochemistry at C-19 does not produce the 6.6.6.5 tetracyclic lanosterol epimer at C-20 but delivers the tricyclic 6.6.5 derivatives $(Z)-6 \mathrm{a}$ and (Z)-7a. It results from partial polycyclizations that do not involve the participation of the $\Delta^{18-19}$ double bond [Scheme 4$]^{[18]}$. This is a behavior shared with the 18,19-dihydrosqualene 2,3-oxide missing the $\Delta^{18-19}$ double bond $^{[20]}$.

Since then, a few other oxidopolyenes have been reacted with OSC-PL, and it was observed that the amount of tetracyclic compounds over the tricyclic ones decreases dramatically by increasing the length of the side chain attached at C-19 in the $\Delta^{18-19}$ unnatural $(Z)$-series, whereas the reverse was found in the $(E)$-series ${ }^{[17221]}$.

We then became aware that changing the stereochemistry of the oxidopolyene has a dual impact on its interactions with the enzyme: It increases the interaction on the one side (trans to the hydrogen at C-18), but, at the same time, it decreases the interactions with the other side (cis to the hydrogen at C-18). We therefore decided to study the behavior, towards pig liver OSC- $\mathrm{PL}^{[19]}$, of oxidosqualene analog 1 bearing at C-19 two alkyl groups different from a methyl group.

We now report that the 2,3-oxidosqualene analog 1c bearing two ethyl at C-19 mainly produces the lanosterol analog $1 \mathrm{c}$ bearing two ethyl groups at C-20 (Scheme 3, entry c), whereas its higher homolog $1 \mathrm{~d}$ bearing two propyl groups there is recovered unchanged under similar or even more drastic conditions ( 3 or $7 \mathrm{~h}$ reaction at $22^{\circ} \mathrm{C}$, Scheme 3 , entry d), suggesting that it is not accepted by the enzyme. Interestingly, constraining the mobility of those two chains by incorporating them into a five-membered ring as in $1 \mathrm{e}$ or a six-membered cycle as in $\mathbf{1 f}$ is not deleterious for the formation of the lanosterol analogs $3 \mathrm{e}$ and $3 \mathrm{f}$ (Scheme 3, entries e and f).

Testing the behavior of 2,3-oxidosqualene analog $1 \mathrm{~g}$ bearing at C-19 an ethyl and a propyl group towards pig liver OSC-PL was obviously our next objective, hoping that at least one of the two stereoisomers at $\Delta^{18-19}$ would cyclize.

We laboriously prepared each of the two stereoisomers $(E)-1 \mathrm{~g}$ and $(Z)-\mathbf{1 g}$ in pure form and unexpectedly found that each of them on incubation with pig liver OSC-PL delivers, in fair yields, lanosterol analog $3 g$ 


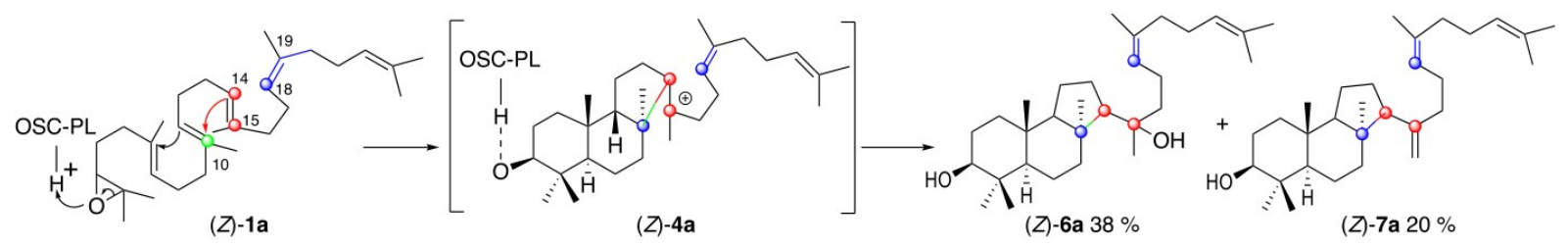

Scheme 4. Results concerning the transformation of a stereoisomeric 2,3-oxidosqualene by OSC-PL.

possessing a propyl and an ethyl group at C-20 [Scheme 5]. Careful investigations and comparison of the biosynthetic compounds with authentic sample of (20S)-3g and (20R)-3g synthesized independently, as reported below, unambiguously shows that the oxidosqualene $(E)-1 \mathrm{~g}$ possessing a $E-\Delta^{18-19} \mathrm{C}, \mathrm{C}$ double bond produces the lanosterol analog $(R)$-3g possessing the $(20 R)$-stereochemistry in $43 \%$ yield (Scheme 5, entry a), whereas its $Z-\Delta^{18-19}$ stereoisomer $(Z)$-1g delivers in $54 \%$ yield a 79/21 mixture of $(S)$-3g and $(R)-\mathbf{3 g}$, in which the former prevails (Scheme 5, entry $\mathbf{b}$ ).

The results in Schemes 3-5 clearly show the importance of the length of the chains attached at C-19 on 2,3oxidosqualene analogs towards OSC-PL. Comparing the results reported in Scheme 5 to those disclosed in Scheme 3, entry d, suggests the exceptional role of an "added carbon" in preventing the quite far removed oxido moiety from reaching the enzymic active site. Comparison of the behavior of $1 \mathrm{~g}$ to that of $\mathbf{1 b}$ (Schemes 3-5, entries a and b) leads to a change in the status of the process from stereospecific to stereoselective.

The Corey model (Scheme 2, entry $\mathbf{b})^{[14,15]}$ fits well to rationalize the formation of (20R)-3g from the oxidosqualene analog $(E)$-1g (Scheme 6 , entry a) as well as that of the major diastereoisomer of the sterol (20S)-3g obtained from the oxidosqualene analog $(Z)-19$.

It is however less obvious to apply the Corey model to the formation of the minor isomer (20R)-3g from $(Z)$ -1g (Scheme 6, entry b) since it requires an anticlockwise rotation of $120^{\circ}$ of the side chain around the $\mathrm{C}_{17}-\mathrm{C}_{20}$ bond before the series of Wagner-Meerwein backbone migrations takes place.

A related $120^{\circ}$ rotation around the $\mathrm{C}_{17}-\mathrm{C}_{20}$ bond in the model disclosed in Scheme 2, entry a, was previously rejected by Corey et al. ${ }^{[14]}$ and is at the origin of its mechanistic model (Scheme 2, entry b) ${ }^{[14,15]}$. It is interesting to note that, although the Corey model could eventually be adapted, as discussed above, the Cornforth model ${ }^{[13]}$ (Scheme 2, entry a) could not be applied to explain this experimental result.

Could it be that the presence of the 3-isohexenyl group in such stereochemical arrangement favors, at least partly, a chair-boat-chair-boat conformation involving the (Z)-1 $\mathbf{g}_{2}$ intermediate [Scheme 7] reminiscent of the original report of the Zurich School [Scheme 1] ${ }^{[9,10]}$ over the chair-boat-chair-chair conformation involving the ( $Z$ ) $-1 \mathrm{~g}_{1}$ intermediate required by the Corey model [Scheme 6$]^{[14,15]}$ ?

In such case, the whole sequence of antiperiplanar additions on $(Z)-1 g_{2}$ would lead to the protosterol $(Z)-2 \mathbf{g}_{3}$ that only requires a $60^{\circ}$ clockwise rotation to initiate the series of migrations leading to $(20 R)-3 \mathrm{~g}$ (Scheme 7; compare to Scheme 6, entry b).

The series of results reported here seems to allow for some fine tuning regarding the interactions between the oxidosqualenes analog 1 and the enzymic environment of OSC-PL. We should refrain from the use of generalizations to deduce the intimate mechanism of lanosterol biosynthesis derived from specific 
a

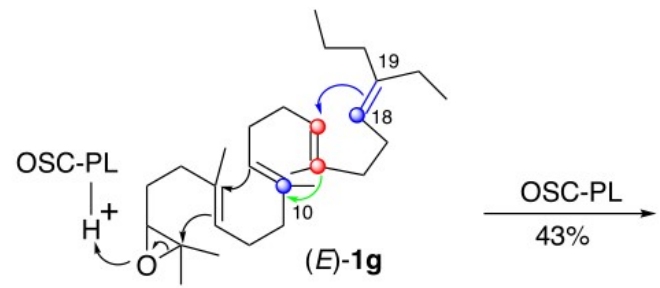

b

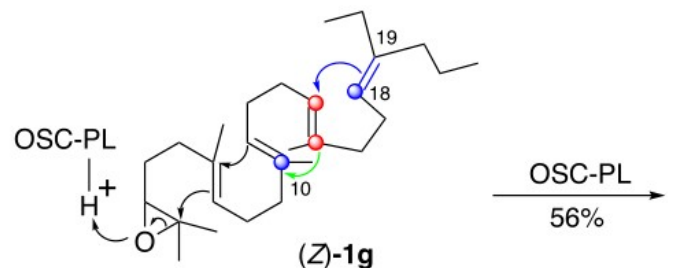

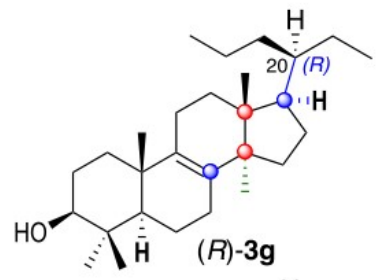

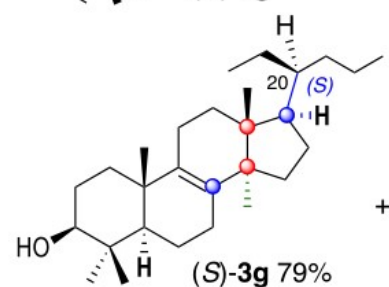

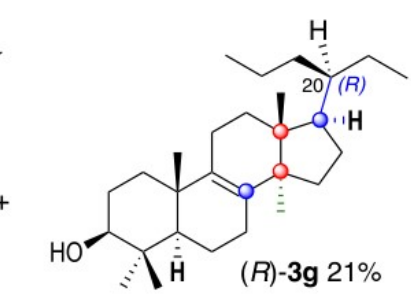

Scheme 5. OSC-PL behavior towards 2,3-oxidosqualene analogs bearing ( $E)$ - and (Z)-stereochemistry at $\Delta^{18-19}$.
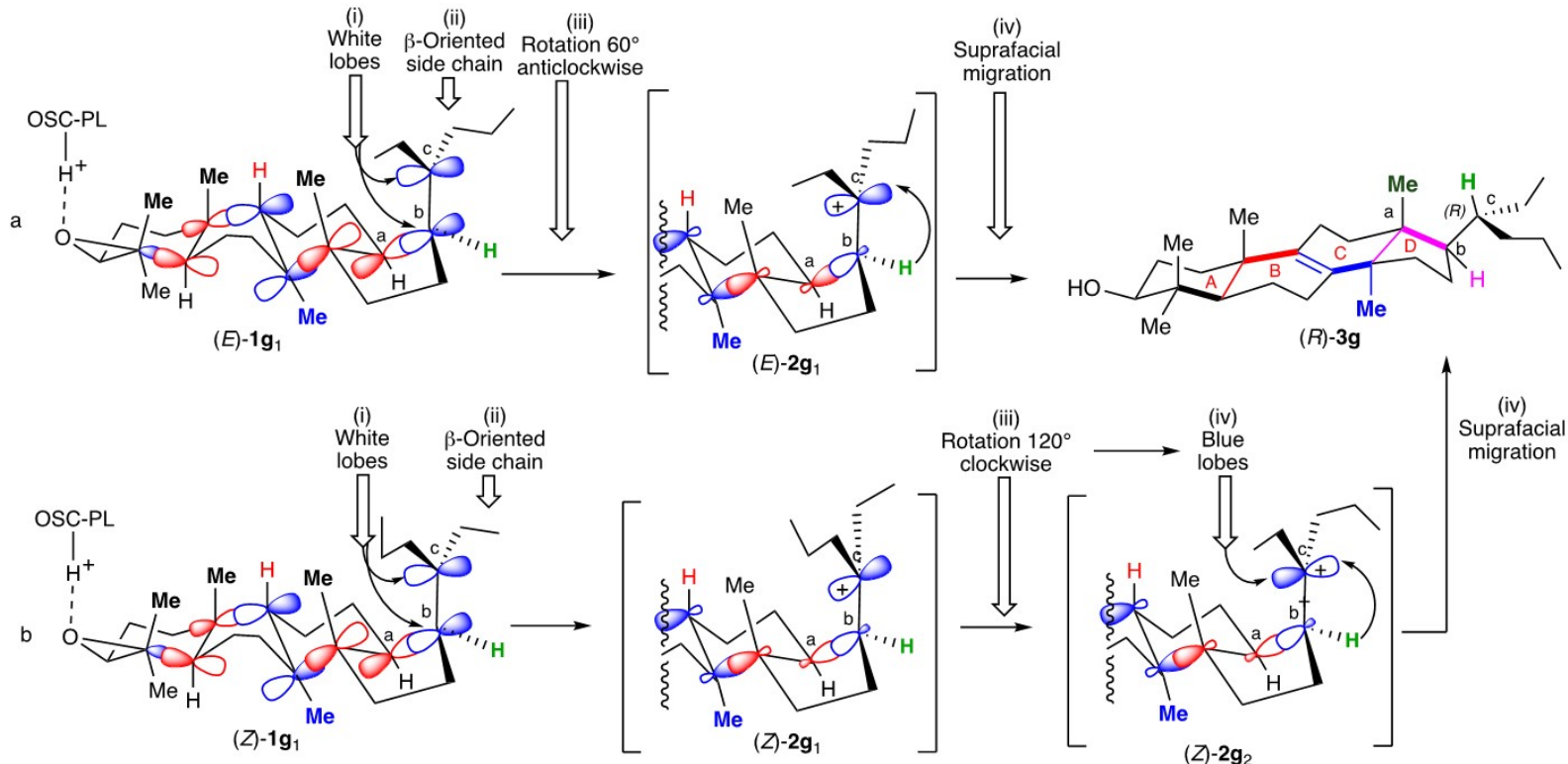

Scheme 6. Rationalizing with the use of the Corey mechanism the formation of $(R)-3 g$ from $(E)-1 g$ and $(Z)-1 g$.
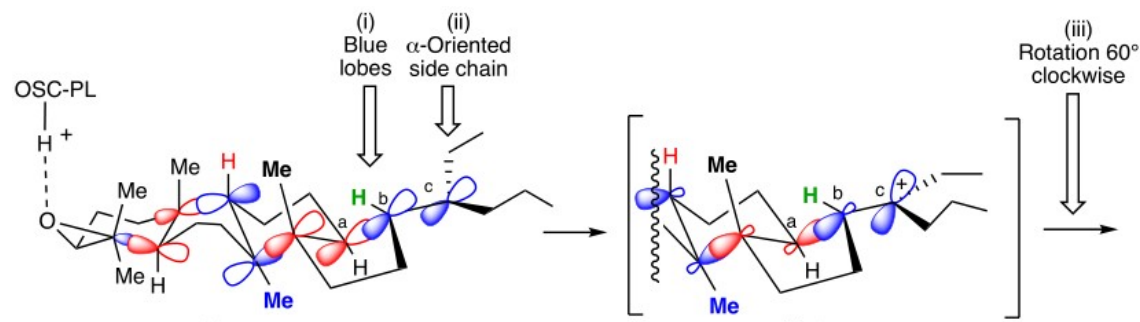

(Z) $-2 \mathrm{~g}_{3}$
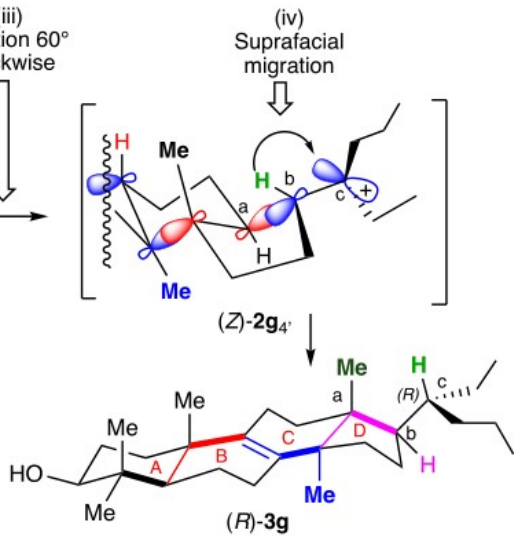

Scheme 7. Rationalizing with the use of the adapted Zurich School mechanism the formation of (R)-3g from (Z)-1g. 
experiments as it has been very often done.

Apparently, OSC-PL possesses an exceptional propensity to adapt its behavior to the substrate, a behavior it does not share for example with its distant ancestor cyclase, OSC-SC, which does not accept at all the $\Delta^{17-18}$ (Z)-analogs of 2,3-oxidosqualene tested ${ }^{[14,17]}$.

\section{EXPERIMENTAL}

This study was carried out on C-14 radiolabeled racemic mixtures of 2,3-oxidopolyene 1 (epimeric at C-3) bearing either $(E)$ - or $(Z)$-stereochemistry at $\Delta^{18-19}$ and therefore the yields were adjusted to the fact that only one enantiomer, the one possessing the $(S)$-stereochemistry at C-3, is biotransformed. The syntheses reported below and "classical" purifications provided at best samples of $1 \mathrm{~g}$ with a content of $10 \%$ of the other diastereoisomer. Isolation of each pure stereoisomer from each $1 \mathrm{~g}$ mixture (HPLC; Hypercarb $100 \mathrm{~mm} \times 4.6 \mathrm{~mm} \times 5 \mathrm{~mm}$ using a gradient from hexane $100 \%$ to hexane/MTBE 80\%/20\%) was carried out in partnership with the "Research Institute For Chromatography" (RIC, Kortrijk, Belgium) headed by Prof. Sandra with whom we have collaborated on many occasions ${ }^{[1,22]}$. RIC also carried out the comparisons of the products resulting from biosynthetic experiments on $(E)-1 \mathrm{~g}$ and $(Z)-1 \mathrm{~g}$ with those of authentic samples of $(S)$-3g and $(R)$-3g prepared as described below [(GC; Column HP-5MS (5\% phenyl, $95 \%$ methyl polysiloxane), $30 \mathrm{~m} \times 0.25 \mathrm{~mm} \times 0.25 \mathrm{~mm}, 100{ }^{\circ} \mathrm{C}$; 1 min then increase $10{ }^{\circ} \mathrm{C} / \mathrm{min}$ until $320{ }^{\circ} \mathrm{C}, 15 \mathrm{~min}$; $(S)$ 3g: rt $33.23 \mathrm{~min},(R)-3 \mathrm{~g}:$ rt $33.53 \mathrm{~min}]$.

\section{Synthesis of 2,3-oxidopolyenes}

The synthesis of the 2,3-oxidopolyenes $1 \mathrm{~d}$-f was achieved [Scheme 8] from the 2,3-oxidopolyenic aldehyde $^{[17,23]} 8$ [Scheme 8] and methylselenoalkyllithium $\mathbf{1 1}^{[24]}$ derived from 2-pentanone 9d, cyclopentanone $\mathbf{9 e}$, and cyclohexanone 9 f [sequential reaction of selenoacetals 10 with: (i) 1 eq. $n$-BuLi, THF, $-78^{\circ} \mathrm{C}, 1 \mathrm{~h}$; (ii) 8 in THF $-78^{\circ} \mathrm{C}, 1 \mathrm{~h}$; and (iii) $\mathrm{H}_{2} \mathrm{O}$ at $\left.\left.-10^{\circ} \mathrm{C}\right]\right]^{[24]}$ followed by treatment of the resulting $\beta$-hydroxyalkylselenide 12 with phosphorus triiodide ( 3 eq. $\mathrm{PI}_{3}, 10$ eq. $\mathrm{NEt}_{3}, \mathrm{CH}_{2} \mathrm{Cl}_{2}, 2{ }^{\circ} \mathrm{C}, 0.5 \mathrm{~h}$ ) according to a protocol described in our laboratory ${ }^{[25]}$ (1d $45 \%$, 1e $35 \%$, and if $33 \%$ yields over two steps). This choice was dictated since the Wittig reaction involving cyclohexylidene triphenylphosphorane provides extremely poor yield of $\mathbf{1 f}(10 \%$ at best).

The 2,3-oxidopolyenic aldehyde $\mathbf{8}$ has been prepared (28\% yield) from squalene and N-bromosuccinimide in $\mathrm{H}_{2} \mathrm{O} / \mathrm{DME}^{[23]}$, followed by treatment with excess $\mathrm{K}_{2} \mathrm{CO}_{3}$ (4.5 eq.) in methanol and ozonolysis of the resulting epoxide (88\% yield) with ozone [(i) 1.2 eq. $\mathrm{CH}_{2} \mathrm{Cl}_{2}$, (ii) excess $\mathrm{Me}_{2} \mathrm{~S}$; yield in 8: 8\%].

The synthesis of $1 \mathrm{~g}$ was performed using Horner-Warren method ${ }^{[26,27]}$ since we were unable to separate the related stereoisomeric mixture of $\beta$-hydroxyalkylselenide $\mathbf{1 2 g}$ [Scheme 8]. Thus, the 2,3-oxidopolyenic aldehyde 8 was reacted with an excess of ylide 14 generated from 3-diphenylphosphinyloxyhexane 13 [(i) 3 eq. 13, 6 eq. LDA, THF, $0{ }^{\circ} \mathrm{C} 0.2 \mathrm{~h}$; (ii) $-78{ }^{\circ} \mathrm{C}$; (iii) 1eq. 8, THF, $-78{ }^{\circ} \mathrm{C}, 0.2 \mathrm{~h}$; (iv) $20^{\circ} \mathrm{C}, 0.5 \mathrm{~h}$; and (v) aq. $\mathrm{NH}_{4} \mathrm{Cl}$ ], leading to a stereoisomeric mixture of $\beta$-hydroxyalkylphosphinyloxide 15 (55\% yield), separated on a silica gel column (ether/pentane of $9 / 1$, as two 90/10 mixtures after several subsequent separations). These were then transformed into $(E)-1$ and $(Z)-1$ g (soiled with $10 \%$ each of the other stereoisomer) in good yields on reaction with $\mathrm{NaH}$ ( 4 eq., THF, $22{ }^{\circ} \mathrm{C}$, yields: $88 \%$ and $89 \%$, respectively). Each mixture (90/10) was further purified by HPLC, as disclosed above.

\section{Synthesis of tritium radiolabeled 2,3-oxidopolyenes}

Radiolabeled 2,3-oxidosqualene analogs $\mathbf{1}^{\star}(967 \mathrm{dpm} / \mathrm{nmol}), \mathbf{1}^{\star}(610 \mathrm{dpm} / \mathrm{nmol})$, and $\mathbf{1 f}^{\star}(547 \mathrm{dpm} / \mathrm{nmol})$ were synthesized from the $\alpha$-tritiated aldehyde $\mathbf{8}^{\star}$ using the protocol described above. The latter was 


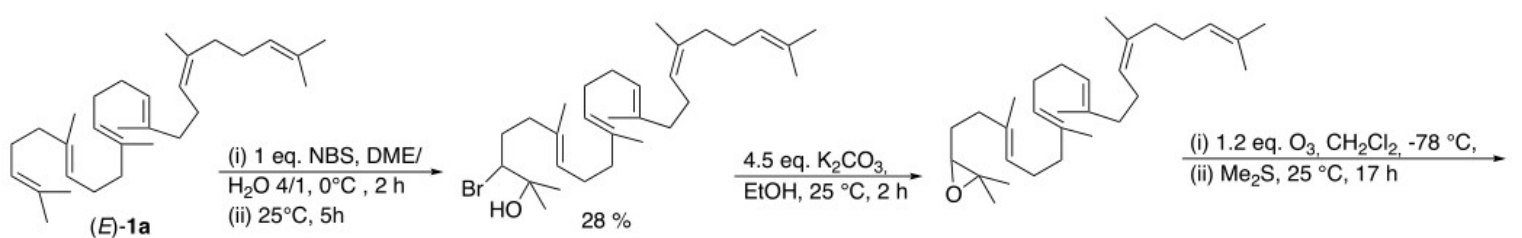

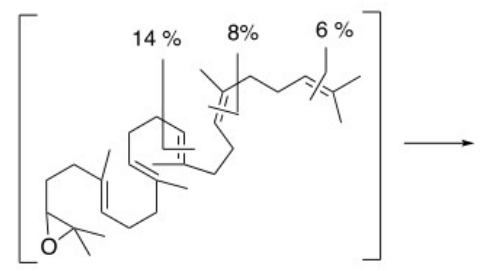
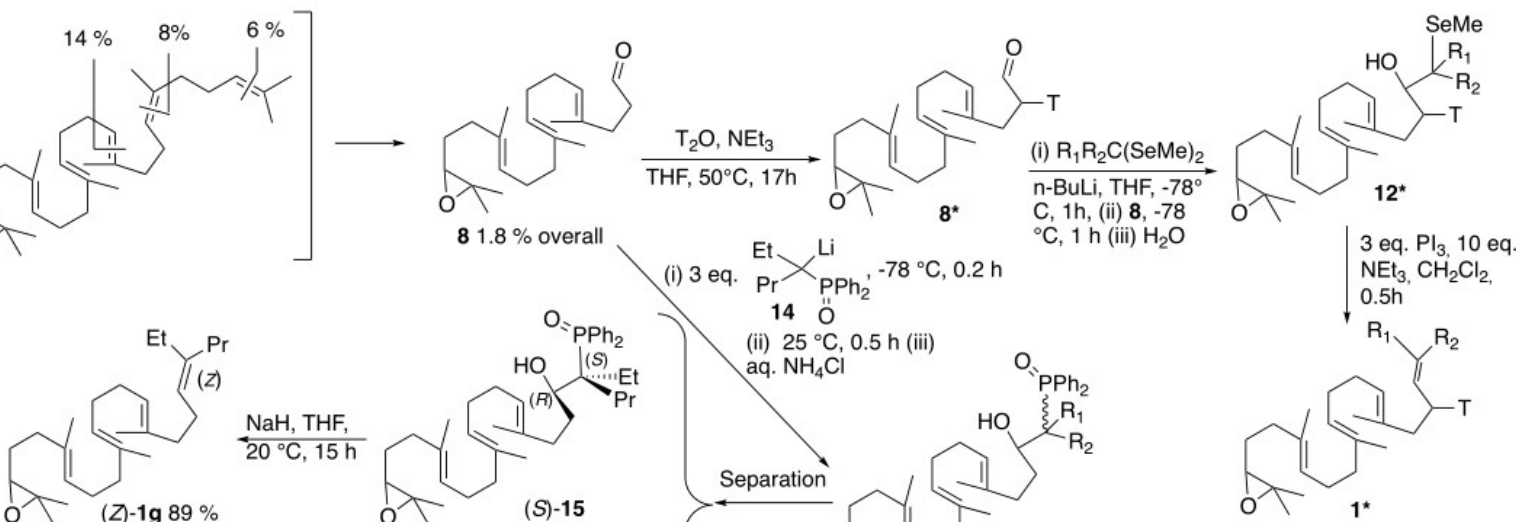

$\mathrm{NaH}, \mathrm{THF}$,

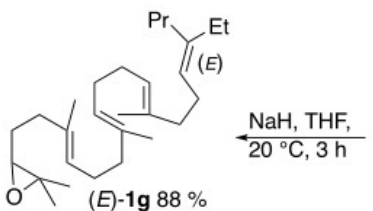

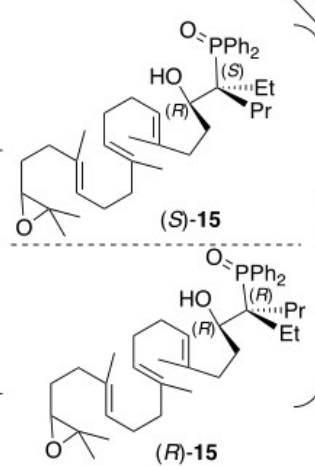

(i) 3 eq. ${ }_{\mathrm{Pr}}^{\mathrm{Et}} \chi_{\mathrm{PPh}_{2}}^{\mathrm{Li}}-78^{\circ} \mathrm{C}, 0.2 \mathrm{~h}$

14 Ö

(ii) $25^{\circ} \mathrm{C}, 0.5 \mathrm{~h}$ (iii)
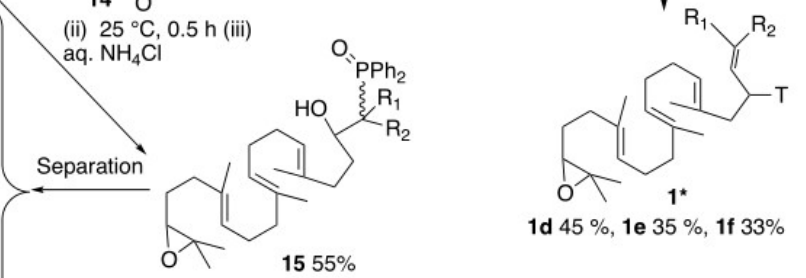

Scheme 8. Description of the synthetic schemes allowing the synthesis of 2,3-oxidosqualene analogs bearing different substituents and stereochemistry at $\Delta^{18-19}$.

generated on heating 8 with $\mathrm{T}_{2} \mathrm{O}$ in the presence of triethylamine $\left(50^{\circ} \mathrm{C}, 15 \mathrm{~h}\right)$ and directly used after usual workup.

A different strategy was used for the synthesis of radiolabeled $1 \mathrm{c}^{\star}(2508 \mathrm{dpm} / \mathrm{nmol})$ as model and $1 \mathrm{~g}$ to avoid the manipulation of radiolabeled material during the tedious separation of the stereoisomers. It was achieved on each stereoisomer after their separation [Scheme 9].

Accordingly, $1 \mathrm{c}$ and each $1 \mathrm{~g}$ stereoisomer were degraded to the corresponding aldehyde by acid catalyzed epoxide ring opening leading to the diol $16\left(70 \% \mathrm{HClO}_{4}, \mathrm{DME} /\right.$ water $\left.3 / 1,0{ }^{\circ} \mathrm{C}, 3 \mathrm{~h}\right)$ and then transformed to the aldehyde 17 (20 eq. $\mathrm{NaIO}_{4}$, aqueous phosphate $\mathrm{pH} 7.2$, methanol, $0{ }^{\circ} \mathrm{C}, 1 \mathrm{~h}, 20{ }^{\circ} \mathrm{C}, 3 \mathrm{~h}$ ), tritiated as disclosed above for other aldehydes, and the resulting $17^{\star}$ was reacted with an excess of isopropylidene triphenylsulfurane to deliver radiolabeled epoxide $\mathbf{1 c},(Z)-\mathbf{1 g}$, and $(E)-\mathbf{1 g}$ [(i) 35 eq. isopropyl diphenyl sulfonium tetrafluoroborate, 35 eq. $\mathrm{CH}_{2} \mathrm{Cl}_{2}, \mathrm{DME},-78^{\circ} \mathrm{C}, 0.5 \mathrm{~h}$; (ii) 1 eq. $17^{*}, \mathrm{DME},-78^{\circ} \mathrm{C}, 2 \mathrm{~h}$; and (iii) $\mathrm{H}_{2}$ O leading to $1 \mathrm{c}^{\star} 48 \%, 2508 \mathrm{dpm} / \mathrm{nmol}$; $(Z)-1 \mathbf{g}^{\star} 44 \%, 578 \mathrm{dpm} / \mathrm{nmol}$; and $\left.(E)-1 \mathbf{g}^{\star} 45 \% 367 \mathrm{dpm} / \mathrm{nmol}\right]$.

\section{Reaction of 2,3-oxidopolyenes with OSC-PL}

The oxidosqualene analogs were reacted with OSC from pig liver prepared according to Hogeboom ${ }^{[19]}$. The conditions used proved to efficiently cyclize 2,3-oxidosqualene (E)-1a to lanosterol (R)-3a in up 80\% yield ( $40 \%$ since the reaction was carried out on epimeric mixture of $(E)-1$ a at C-3).

Accordingly, the radiolabeled 2,3-oxidopolyene 1 (300-2000 $\mathrm{nmol})$ mixed with Tween 80 [10\% in acetone $(10 \%)$ and then evaporation of acetone] and dissolved in bi-distilled water was stirred under argon for $3 \mathrm{~h}$ 

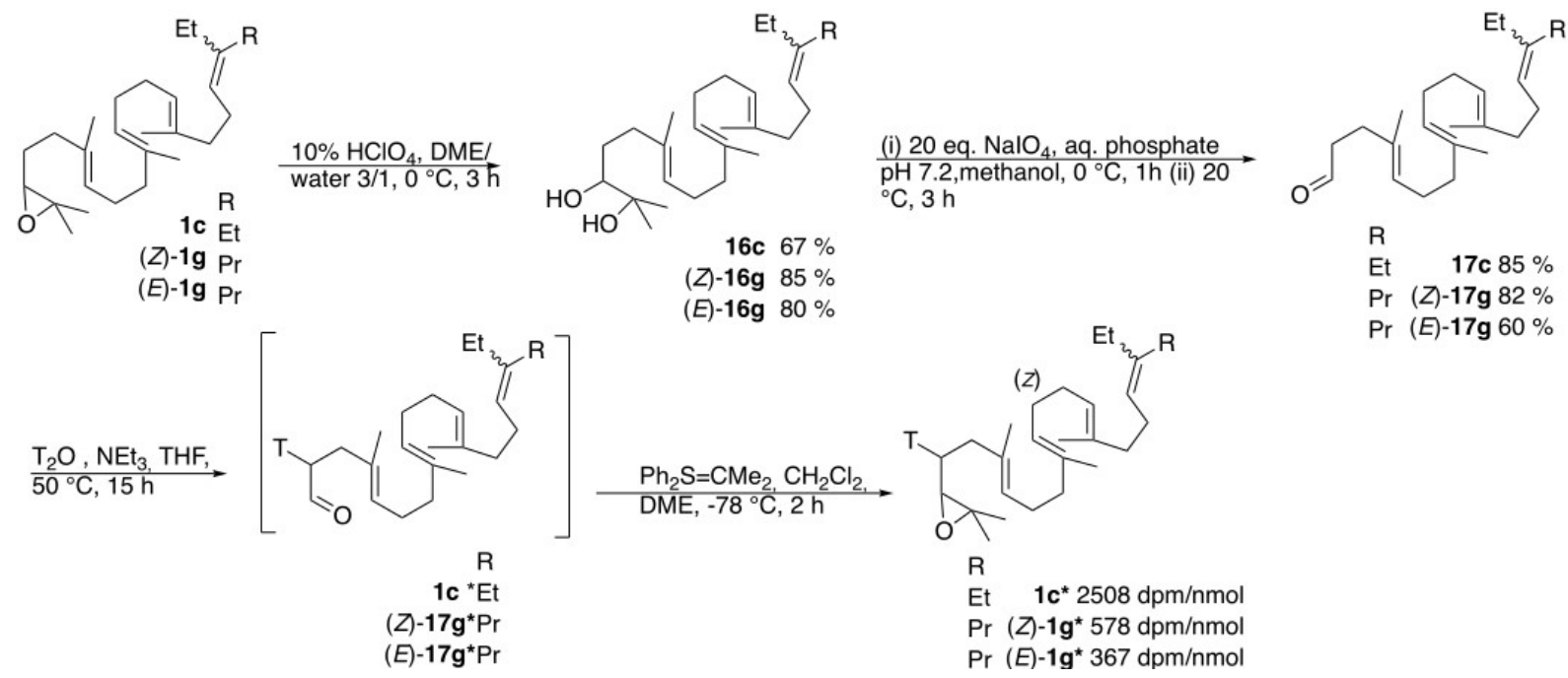

Scheme 9. Transformation of 2,3-oxidosqualenes $1 \mathrm{c}$ and $\mathbf{1 g}$ into their tritium-labeled analogs at C-4.

( $17 \mathrm{~h}$ in the large-scale experiment, $5 \mathrm{mg}$ of 1 ) with an aqueous solution of OSC-PL prepared as discussed above $^{[19]}$. The mixture was then saponified on stirring with a $10 \%$ potassium hydroxide solution in ethanol and extracted with ether, leading to a recovery of compounds possessing $88 \%-95 \%$ of the radioactivity. The crude mixture was separated by preparative layer chromatography $\left(\mathrm{SiO}_{2}\right.$, toluene/ethyl acetate $95 / 05$, and the following products were isolated: recovered oxidosqualene $1, \mathrm{rf}=0.7-0.8$; lanosterol, $\mathrm{rf}=0.4-0.5$; or analogs $3, \mathrm{rf}=0.1-0.2)$. In the case of $\mathbf{1 g}$, the reactions were carried out at $1 \mu \mathrm{mol}$, and the purifications on $\mathrm{SiO}_{2}$ (toluene/ethyl acetate 95/05) led to: from $(Z)-1$, Zone $\mathrm{A}_{\mathrm{Z}}, \mathrm{rf}=0.7-0.8$ (61\%, oxidosqualene); Zone $\mathrm{B}_{\mathrm{Z}}$, $\mathrm{rf}=0.4-0.5$ (54\%, lanosteryl derivatives); and Zone $\mathrm{C}_{Z}, \mathrm{rf}=0.1-0.2$ (11\%, unknown); and, from $(E)-1 \mathrm{~g}$, Zone $\mathrm{A}_{\mathrm{Z}}, \mathrm{rf}=0.6-0.8$ (53\%, oxidosqualene), and Zone $\mathrm{B}_{\mathrm{Z}}, \mathrm{rf}=0.4-0.45$ (43\%, lanosteryl derivatives).

\section{Hemi-synthesis of lanosteryl analogs (R)-3g and (R)-3g}

To unambiguously prove the structure of the compounds resulting from the reaction of $1 \mathrm{~g}$ with 2,3oxidosqualene sterol cyclase, we achieved the hemi-synthesis of the two epimeric (20R)-3g and (20S)-3g from lanosterol $1 \mathrm{a}$ as a common intermediate using a methodology previously used in our laboratory ${ }^{[28,29]}$.

The synthetic strategy involves the following [Schemes 10 and 11]:

(i) Degrade the lanosteryl acetate $\mathbf{1 a}_{\mathrm{Ac}}$ side chain up to C-20, leading to the methyl ketone $\mathbf{2} \mathbf{1}$ in order to destroy the stereochemical information there keeping intact the structure and stereochemistry of the tetracyclic scaffold [Scheme 10] ${ }^{[30]}$.

(ii) Restore the chirality at C-20 by taking advantage of [Scheme 11]: (a) the face-selective addition of nucleophile on the $(\mathrm{Si})$-face of the carbonyl of the ketones 22 directed by the presence of the C-18 methyl group using a nucleophile bearing a leaving group or a potential leaving group able to produce the epoxides 24 [Scheme 9]; and (b) rearrangement of the epoxide $\mathbf{2 4}$ to the intermediate aldehyde 25 on reaction with Grignard reagents that involves the highly stereoselective migration of a hydrogen of the epoxide ring leading mainly to the $(20 R)$-epimers of $25(R=\mathrm{Me}$ or $\mathrm{Et})$ that are trapped in situ by the Grignard reagents. 

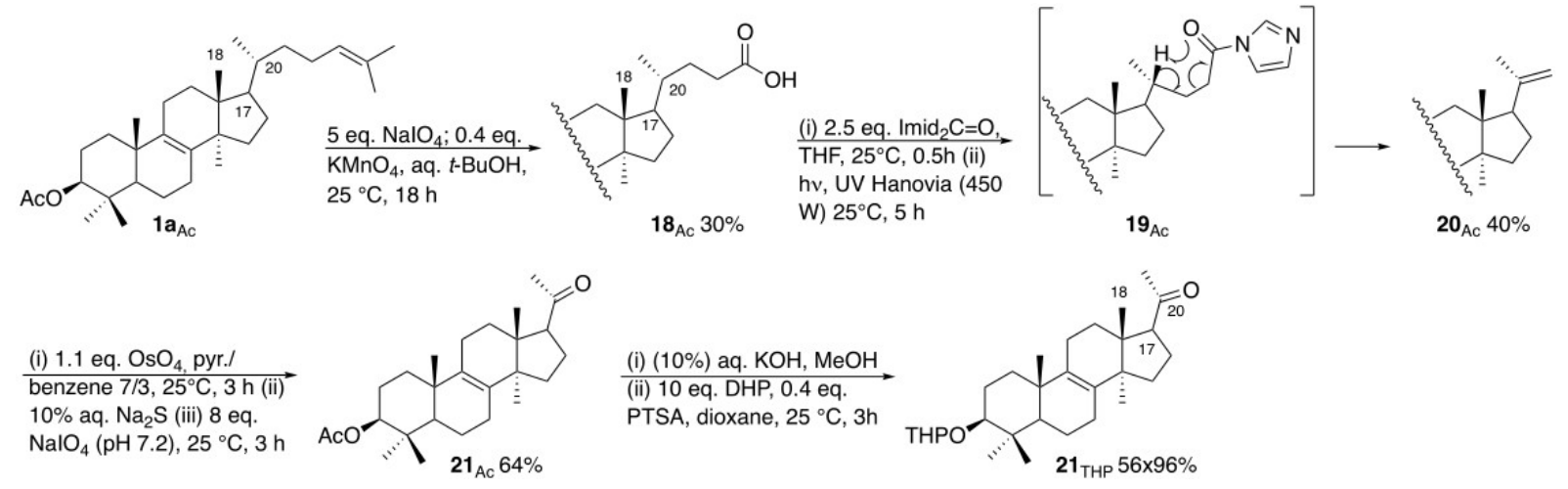

Scheme 10. Description of the synthetic scheme allowing the degradation of the side chain of lanosterol up to C-20.

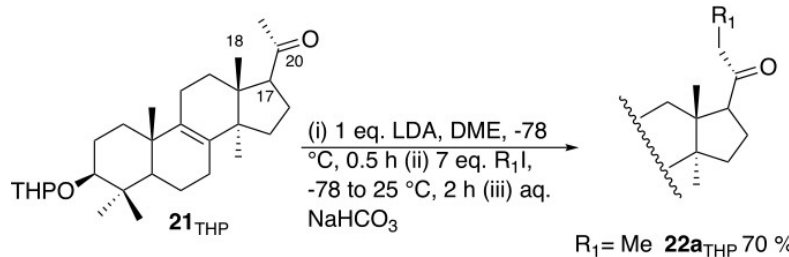

(20 eq. Etl, $\left.-20^{\circ} \mathrm{C}\right)$

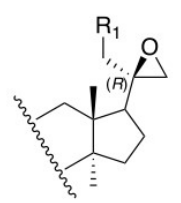

$\mathrm{R}_{1}=$ Me $24 \mathrm{a}_{\mathrm{THP}} 63 \%$ overall $\mathrm{R}_{1}=$ Et $24 \mathrm{~b}_{\mathrm{THP}} 74 \times 70 \%$

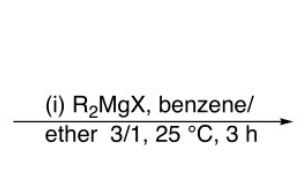

$\mathrm{R}_{2}=\mathrm{Et}, \mathrm{X}=\mathrm{Br}$ $R_{2}=M e, X=1$
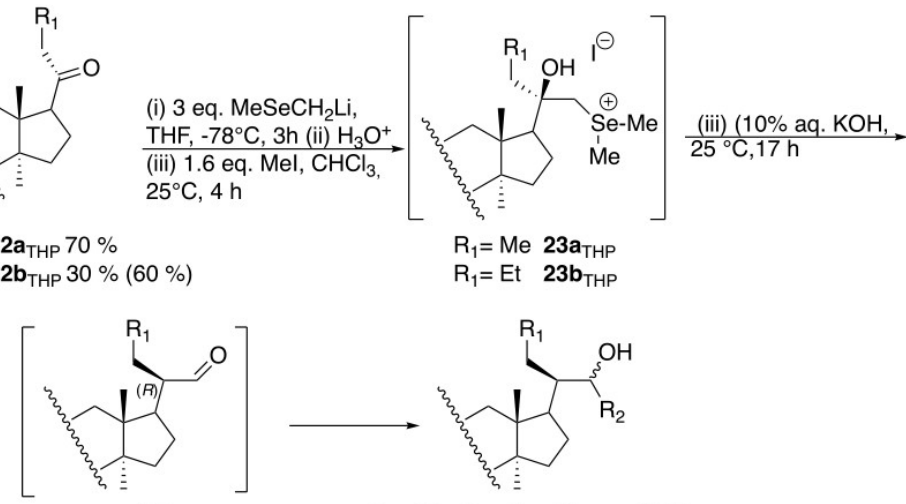

$\mathrm{R}_{1}=\mathrm{Me} 25 \mathrm{a}_{\mathrm{THP}}$ $R_{1}=$ Et $25 b_{\text {THP }}$

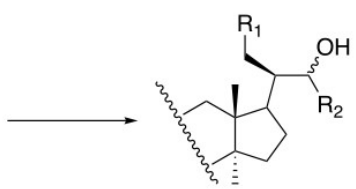

$R_{1}=M e, R_{2}=$ Et $26 a_{T H P} 70 \%$ $\mathrm{R}_{1}=\mathrm{Et}, \mathrm{R}_{2}=\mathrm{Me} \quad \mathbf{2 6} \mathrm{b}_{\mathrm{THP}} \mathbf{7 4} \%$

Scheme 11. Stereoselective introduction of asymmetric C-20 carbon precursors of lanosteryl analogs (R)-3g and (S)-3g.

(iii) Synthesize both epimeric derivatives (20R)-3g and (20S)-3g that involve the electrophilic alkylation $\left(\mathrm{R}_{1}\right.$ $\mathrm{X}, \mathrm{X}=$ halogen, $\left.\mathrm{R}_{1}=\mathrm{Me}, \mathrm{Et}\right)^{[31]}$ of the methyl ketone 21 and later the nucleophilic alkylation $\left(\mathrm{R}_{2}-\mathrm{MgX}, \mathrm{R}_{2}=\right.$ Et, $\mathrm{Me}$ ) of the aldehyde 25 using the same series of reactions but inverting the sequential introduction of methyl and ethyl groups to access either to (20R)-3g $\left(\mathrm{R}_{1}=\mathrm{Me}, \mathrm{R}_{2}=\mathrm{Et}\right)$ through (22a and 26a, Scheme 11) or to (20S)-3g $\left(\mathrm{R}_{1}=\mathrm{Et}, \mathrm{R}_{2}=\mathrm{Me}\right)$ through (22b and $\mathbf{2 6} \mathbf{b}$, Scheme 11).

A transformation related to that of $\mathbf{2 6}$ to $\mathbf{3 g}$ was originally performed in our laboratory ${ }^{[28]}$, and is disclosed in Scheme 12 , entry a. It allows the synthesis of $(R)$ - $\mathbf{3} \mathbf{g}$ through the oxidation of $\mathbf{2 6} \mathbf{b}_{\mathrm{THP}}$ and then acid catalyzed deprotection leading to $27 \mathbf{b}$. The former reaction was readily achieved by using excess of PCC in the presence of sodium acetate ( 5 eq. PCC, 0.3 eq. $\left.\mathrm{AcONa}, \mathrm{CH} 2 \mathrm{Cl} 2,25^{\circ} \mathrm{C}, 3 \mathrm{~h}\right)^{[32]}$. However, we experienced unexpected drawbacks in the synthesis of the thioacetal $28 \mathrm{~b}$ from $27 \mathrm{~b}$. We could not extend to $27 \mathrm{~b}$ the method used ( $\mathrm{HS}-\mathrm{CH}_{2}-\mathrm{CH}_{2}-\mathrm{SH}, \mathrm{BF}_{3} \cdot \mathrm{Et}_{2} \mathrm{O}, \mathrm{AcOH}, 25^{\circ} \mathrm{C}$ ) on a closely related ketone ${ }^{[30]}$. Neither alternative methods disclosed by Evans et al. ${ }^{[33]}$ such as $\left(\mathrm{Me}_{3} \mathrm{Si}-\mathrm{S}-\mathrm{CH}_{2}-\mathrm{CH}_{2}-\mathrm{S}-\mathrm{SiMe}_{3}, \mathrm{ZnI}_{2}, \mathrm{Et}_{2} \mathrm{O}, 24 \mathrm{~h}\right)$ or the more conventional ones [HS- $\mathrm{CH}_{2}-\mathrm{CH}_{2}-\mathrm{SH}$ (15 eq.), $\mathrm{ZnCl}_{2}$ (8 eq.), $\mathrm{CH}_{2} \mathrm{Cl}_{2}, 25^{\circ} \mathrm{C}, 8 \mathrm{~h}$ ] proved to be successful to reach our goal. The latter reaction however, when carried out for longer time ( $48 \mathrm{~h}$ instead of $8 \mathrm{~h})$, delivered the thioacetal $\mathbf{2 8 b}$ in modest yield (51\%, Scheme 9). Reduction of the latter with lithium in ethylamine [(i) 250 eq. $\mathrm{Li}, \mathrm{EtNH}_{2}{ }^{\prime}-25^{\circ} \mathrm{C}, 0.7 \mathrm{~h}$; and (ii) aq. $\mathrm{NH}_{4} \mathrm{Cl}$ ] affords $(R)$-3g in $43 \%$ yield along with $(S)$ - $3 \mathrm{~g}(15 \%)$ and one unidentified product. 

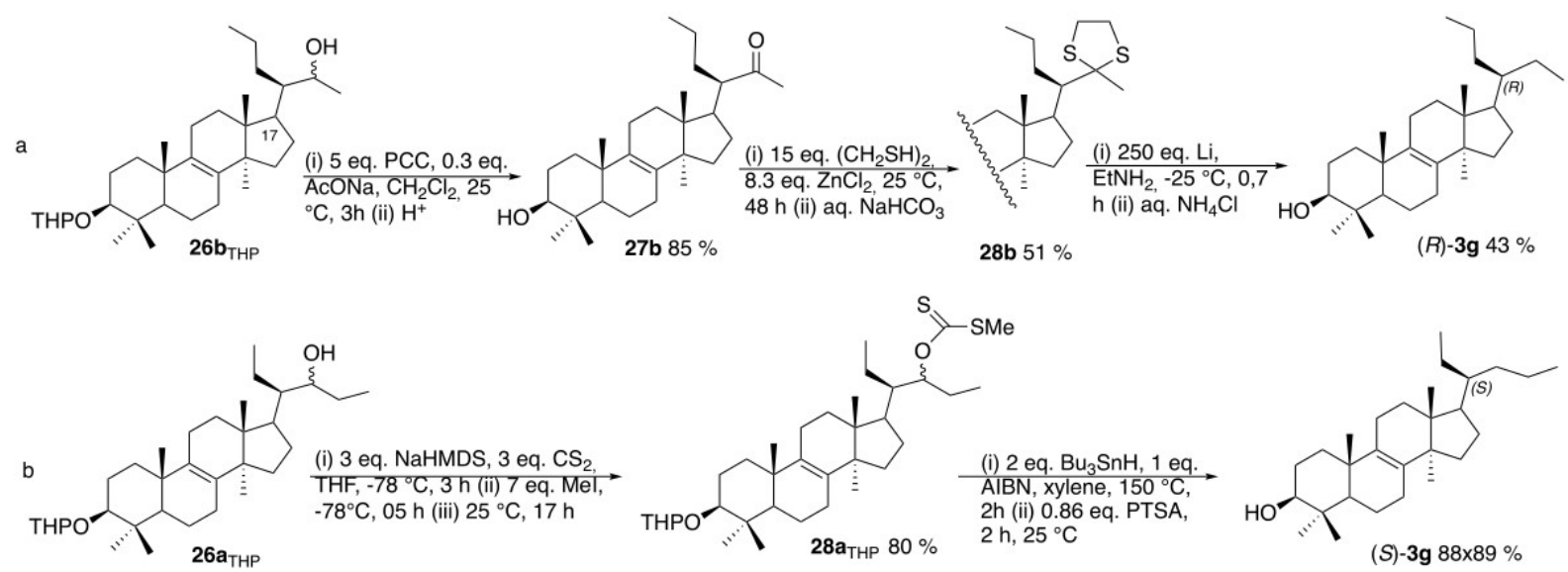

Scheme 12. Final steps towards the synthesis of lanosteryl analogs (R)-3g and (S)-3g.

Due to the difficulty encountered in the transformation disclosed above, we decided to adopt a different strategy to transform 26a into (S)-3g (Scheme 12, entry b) that involves the formal reduction of the alcohol $\mathbf{2 6}_{\mathrm{THP}}$. It was efficiently achieved by modification of the well-known Barton-McCombie method ${ }^{[34]}$ that uses the reduction of the related xanthate.

The synthesis of the xanthate $\mathbf{2 8 \mathbf { a } _ { \mathrm { THP } }}$ was readily achieved [(i) 3 eq. NaHMDS, 3 eq. $\mathrm{CS}_{2}$, THF, $-78^{\circ} \mathrm{C}$, $3 \mathrm{~h}$; (ii) 7 eq. MeI, $-78^{\circ} \mathrm{C}, 05 \mathrm{~h}$; and (iii) $25^{\circ} \mathrm{C}, 17 \mathrm{~h}, 80 \%$ ], but neither its reduction with tin hydride in the presence of azo-bis-isobutyronitrile (AIBN) as a radical initiator ( 1.5 eq. $\mathrm{Bu}_{3} \mathrm{SnH}$, xylene, reflux, $15 \mathrm{~h}$ ) according to the original procedure ${ }^{[34]}$ nor those involving 2 eq. $\mathrm{Bu}_{3} \mathrm{SnH}$ and 1 eq. AIBN in toluene $\left(110^{\circ} \mathrm{C}, 2 \mathrm{~h}, 10 \%\right.$ yield) worked properly. However, we found that performing the reaction at high temperature but for a short time to avoid the degradation of the product proved to be an excellent alternative ( 2 eq. $\mathrm{Bu}_{3} \mathrm{SnH}, 1$ eq. AIBN, xylene, $150^{\circ} \mathrm{C}, 2 \mathrm{~h}, 88 \%$ ).

Both alcohols (20R)-3g and (20S)-3g were acetylated ( $\mathrm{Ac}_{2} \mathrm{O}$, pyridine, $\left.25^{\circ} \mathrm{C}, 17 \mathrm{~h}\right)$, delivering $(20 R)-\mathbf{3} \mathrm{g}_{\mathrm{Ac}}$ and $(20 S)-3 \mathbf{g}_{\mathrm{Ac}}$ in $84 \%$ yield. Those acetates proved to contain $10 \%$ of the other diastereoisomer $(15 \%$ and $10 \%$, respectively), probably arising from the rearrangement of the epoxide with the Grignard reagent step that is less stereoselective than expected ${ }^{[28,29]}$.

\section{CONCLUSIONS}

We report the original behavior of OSC-PL towards oxidosqualene analogs bearing two alkyl groups at $\mathrm{C}_{19}$ by the incremental addition of a methyl group from: (a) Me,Et (tetracyclic, stereospecific) ${ }^{[16,17]}$; (b) Et,Et (tetracyclic); (c) Et,Pr (tetracyclic, non-stereospecific); and (d) $\operatorname{Pr} ; \operatorname{Pr}$ (no cyclization). It adds to the previous work that includes: (e) Me, isohexenyl (tetracyclic/tricylic non-chemospecific) ${ }^{[18]}$; (f) saturated $\mathrm{C}_{18}-\mathrm{C}_{19}$ bond (tricyclic) $)^{[20]}$; and (g) Me, isohexadienyl (tetracyclic, protosterol) ${ }^{[14]}$. We observed the exceptional ability of this enzyme to respond in a different manner to different substrate analogs, providing each time products possessing a different type of structure.

We also propose an original hypothesis to rationalize the formation for the first time of a lanosterol analog bearing the natural stereochemistry at C-20 from an oxidosqualene analog bearing a non natural stereochemistry at $\Delta^{18-19}$. A possible support for this hypothesis could arise from reacting OSC-PL with an oxidosqualene analog bearing one [Figure $1,(Z)-\mathbf{1 h}$ or $(Z)-1 \mathbf{i}$ ] or two unsaturations [Figure 1, $(Z)-\mathbf{1 j}$ ] on the side chain hoping that protosterols bearing the side chain lying in alpha-position would be isolated using a 


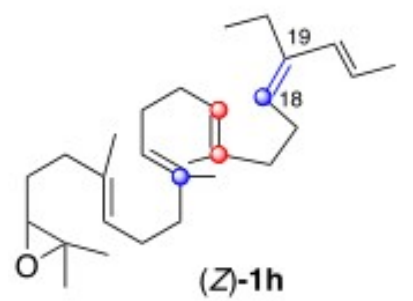

$(Z)-1 \mathrm{~h}$

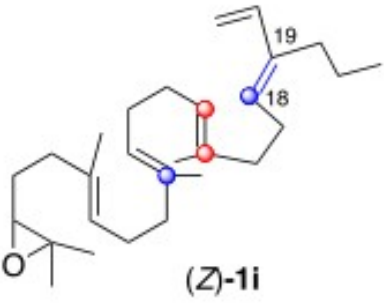

$(Z)-1 \mathbf{i}$

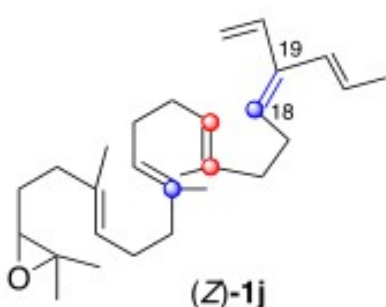

$(Z)-1 \mathrm{j}$

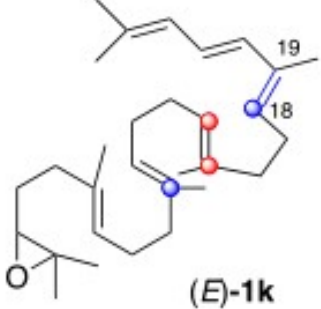

(E)-1k

Figure 1. Potential precursors of protesterols bearing a side-chain lying in alpha-position.

strategy similar to the one developed by Corey et al.$^{[14]}$ using $(Z)-1 \mathbf{k}$ [Figure 1] to support his proposal reported in Scheme 2, entry $\mathbf{b}^{[14,15]}$. Modeling in silico the process is another alternative that we are pursuing using the detailed X-ray structure of human sterolcyclase reported by Thoma et al. ${ }^{[5]}$.

\section{DECLARATIONS}

\section{Acknowledgments}

The authors acknowledge the fundamental technical assistance of M. Alain Burlet and of Mrs Anne-Marie Laval. Alain Krief is grateful to Dr. Lucy Stark for the extremely useful translation of this master piece scientific paper - Revisited after 50 Years: The "Stereochemical Interpretation of the Biogenetic Isoprene Rule for the Triterpenes".

\section{Authors' contributions}

Made similar contributions to conception and design of the study and performed data analysis and interpretation: Krief A, Sable R, Ronvaux A, Dumont W, Sandra P, David F

\section{Availability of data and materials}

Data are deposited at the Universite of Namur in the PhD theses of Dr. Alain Ronvaux (1998) and Dr. Romuald Sable (2007) and are accessible on request.

\section{Financial support and sponsorship}

This work has been supported by doctoral fellowships to Alain Ronvaux and to Romuald Sable from the FRIA (Fund for Research Training in Industry and Agriculture) from the Belgian Science Foundation (FNRS). The authors thank FNRS and the Facultés Universitaires Nôtre Dame de la Paix (FUNDP) for their financial support. Alain Krief deeply thanks Professor Charles Jaumotte previous General Admministrator of the University N. D de la Paix, Namur and the members of its Administration Council for generous financial support and encouragements.

\section{Conflicts of interest}

All authors declared that there are no conflicts of interest.

\section{Ethical approval and consent to participate}

Not applicable.

\section{Consent for publication}

Written informed consent for publication was obtained for all the authors and from Dr. Willy Dumont wife (Mrs Josiane Gerlache) and one of his sons (Professor Patrick Dumont, UCL, Louvain le Neuve, Belgium). 


\section{Copyright}

(c) The Author(s) 2021.

\section{REFERENCES}

1. Barrett A, Ma T, Mies T. Recent developments in polyene cyclizations and their applications in natural product synthesis. Synthesis 2018;51:67-82. DOI

2. Yoder RA, Johnston JN. A case study in biomimetic total synthesis: polyolefin carbocyclizations to terpenes and steroids. Chem Rev 2005; 105:4730-56. DOI PubMed PMC

3. Huff MW, Telford DE. Lord of the rings - the mechanism for oxidosqualene:lanosterol cyclase becomes crystal clear. Trends Pharmacol Sci 2005;26:335-40. DOI PubMed

4. Harrison DM. The biosynthesis of triterpenoids and steroids. Nat Prod Rep 1985;2:525-60. DOI PubMed

5. Thoma R, Schulz-Gasch T, D'Arcy B, et al. Insight into steroid scaffold formation from the structure of human oxidosqualene cyclase. Nature 2004;432:118-22. DOI PubMed

6. Woodward RB, Bloch K. The cyclization of squalene in cholesterol synthesis. J Am Chem Soc 1953;75:2023-4. DOI

7. Stork G. The stereochemistry of polyene cyclization. Harvard University Organic colloquium Abstract. 1950. Burgstahler AW, PhD. Thesis. Harvard University: 1952.

8. Stork G, Burgstahler AW. The stereochemistry of polyene cyclization. J Am Chem Soc 1955;77:5068-77. DOI

9. Eschenmoser A, Ruzicka L, Jeger O, Arigoni D. Zur Kenntnis der Triterpene. 190. Mitteilung. Eine stereochemische Interpretation der biogenetischen Isoprenregel bei den Triterpenen. Helv Chim Acta 1955;38:1890-904. DOI

10. Eschenmoser A, Arigoni D. Revisited after 50 years: the "stereochemical interpretation of the biogenetic isoprene rule for the triterpenes". HCA 2005;88:3011-50. DOI

11. Corey EJ, Russey WE, Ortiz de Montellano PR. 2,3-Oxidosqualene, an intermediate in the biological synthesis of sterols from squalene. J Am Chem Soc 1966;88:4750-1. DOI PubMed

12. Tamelen EE, Willett JD, Clayton RB, Lord KE. Enzymic conversion of squalene 2,3-oxide to lanosterol and cholesterol. J Am Chem Soc 1966;88:4752-4. DOI PubMed

13. Cornforth JW. Olefin alkylation in biosynthesis. Angew Chem Int Ed Engl 1968;7:903-11. DOI PubMed

14. Corey EJ, Virgil SC, Sarshar S. New mechanistic and stereochemical insights on the biosynthesis of sterols from 2,3-oxidosqualene. $J$ Am Chem Soc 1991;113:8171-2. DOI

15. Wendt KU, Schulz GE, Corey EJ, Liu DR. Enzyme mechanisms for polycyclic triterpene formation. Angew. Chem. Int. Edn Engl 2000; 39:2812-33. DOI

16. Hérin M, Sandra P, Krief A. Stereospecific enzymic cyclization of a synthetic 2,3-oxidosqualene analogue bearing an $18 \mathrm{Z}$ carboncarbon double bond. Tetrahedron Letters 1979;20:3103-6. DOI

17. Krief A, Pasau P, Guittet E, Shan YY, Hérin M. Novel results on the biocyclisation of 2,3-oxidosqualene analogs by sterol cyclase. Bioorganic \& Medicinal Chemistry Letters 1993;3:365-8. DOI

18. Krief A, Schauder JR, Guittet E, Herve du Penhoat C, Lallemand JY. About the mechanism of sterol biosynthesis. J Am Chem Soc 1987;109:7910-1. DOI

19. Hogeboom GH. Methods enzymol. Fractionation of cell components of animal tissues. Elsevier; 1955. p. 16-9. DOI

20. Tamelen EE, Sharpless KB, Hanzlik R, Clayton RB, Burlingame AL, Wszolek PC. Enzymic cyclization of trans, trans, trans-18,19dihydrosqualene 2,3-oxide. J Am Chem Soc 1967;89:7150-1. DOI PubMed

21. Krief A, Pasau P, Quéré L. Comparison of the behavior of oxidosqualene cyclases from pig liver and yeast toward epoxy-squalene analogues possessing a $\Delta^{18-19} \mathrm{Z}$ or E (C, C) double bond. Bioorganic \& Medicinal Chemistry Letters 1991;1:365-8. DOI

22. Krief A, Dunkle M, Bahar M, Bultinck P, Herrebout W, Sandra P. Elucidation of the absolute configuration of rhizopine by chiral supercritical fluid chromatography and vibrational circular dichroism. J Sep Sci 2015;38:2545-50. DOI PubMed

23. Tamelen E, Sharpless KB. Positional selectivity during controlled oxidation of polyolefins. Tetrahedron Letters 1967;8:2655-9. DOI

24. Krief A, Dumont W, Clarembeau M, Bernard G, Badaoui E. Synthesis of $\alpha$-selenoalkyllithium compounds. Tetrahedron 1989;45:2005-22. DOI

25. Labar D, Krief A. Connective (C-C) route to hindered epoxides and olefins from hindered ketones. J Chem Soc, Chem Commun 1982;10:564-6. DOI

26. Horner L, Hoffmann H, Wippel HG, Klahre G. Phosphororganische Verbindungen, XX. Phosphinoxyde als Olefinierungsreagenzien. Chem Ber 1959;92:2499-505. DOI

27. Buss AD, Warren S. The Wittig-Horner route to tri-substituted alkanes: synthesis of - $\alpha$-bisabolene. Tetrahedron Letters 1983;24:1114. DOI

28. Schauder J, Krief A. Regio and stereochemically controlled ring opening of epoxides with Grignard reagents. Stereocontrolled synthesis of the steroid side chains. first stereoselective hemisynthesis of 20s isolanosterol. Tetrahedron Letters 1982;23:4389-92. DOI

29. Koreeda M, Koizumi N. Stereochemically controlled synthesis of 20-isocholesterol. Tetrahedron Letters 1978;19:1641-4. DOI

30. Pasau P. PhD thesis, Facultés Universitaires Notre-Dame de la Paix (FUNDP). Namur; 1992.

31. House HO, Gall M, Olmstead HD. Chemistry of carbanions. XIX. Alkylation of enolates from unsymmetrical ketones. J Org Chem 1971;36:2361-71. DOI PubMed

32. Corey EJ, Suggs JW. Pyridinium chlorochromate. An efficient reagent for oxidation of primary and secondary alcohols to carbonyl 
compounds. Tetrahedron Letters 1975;16:2647-50. DOI

33. Evans DA, Truesdale LK, Grimm KG, Nesbitt SL. Thiosilanes, a promising class of reagents for selective carbonyl protection. $J \mathrm{Am}$ Chem Soc 1977;99:5009-17. DOI

34. Barton DHR, Mccombie SW. A new method for the deoxygenation of secondary alcohols. J Chem Soc, Perkin Trans 1 1975. DOI 